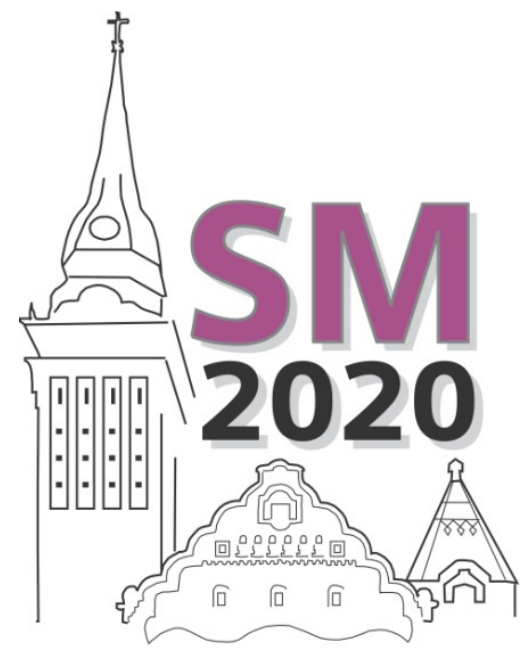

Miller Alexander

Dostoevsky Omsk State University, Omsk, Russia

e-mail: aem55@yandex.ru 25th International Scientific Conference

Strategic Management and Decision Support Systems

in Strategic Management

$19^{\text {th }}$ May, 2020, Subotica, Republic of Serbia

\title{
MODELS OF TECHNOLOGICAL INTEGRATION DEVELOPMENT
}

\begin{abstract}
Issues of scientific and technological development of the economy, increasing its competitiveness, including various aspects of technological integration, are the subject of foreign and domestic research. At the same time, technological integration is considered as a key direction of the new industrial and scientific-technical policy, as a means of transition to the digital economy, to production processes with higher added value, as a means of establishing a constructive dialogue between industrial enterprises and science.

The key problem is the inability to meet the growing demand for products, to stop the critical decline in the share of domestic products in the domestic market and to neutralize the threat of loss of national security of the country. In order to achieve sustainable economic growth, it is necessary to develop state policies aimed at creating new economic institutions. At the same time, it should be emphasized that new sectors of the economy, as priority areas of scientific and technological development, should become the main consumers of scientific and technical products.

The purpose of the article is to study the problems of modeling the development of technological integration in the context of priority scientific and technological development of the Russian economy.

The article uses a wide range of general scientific methods: analysis and synthesis, grouping, typing, modeling, economic-statistical and graphical. The main methodological approaches used in the article are: structural-functional, instrumental and process approaches, which are reflected in the scientific and practical material of the general theory of systems, the theory of organization.

The processes of formation and development of technological integration represent an insufficiently researched area. The reason for this is, on the one hand, the relative novelty of this economic phenomenon, and, on the other hand, the lack of theoretical and methodological tools for modeling the development of technological integration. The study provides a theoretical justification for the organizational model of technological integration development as a dynamic set of interrelated modules: management and coordination; structure; processes; resources, the purpose of which is to achieve the strategic goals of participants in technological integration. There was proved a process model of technological integration development, and there was carried out its decomposition, which allows us to identify the main, supporting and regulatory processes of participants in technological integration. The combination of these models helps to manage these processes in order to achieve maximum efficiency of the modern economy.
\end{abstract}

Keywords: technological integration, organizational model, process model, development priorities, modeling

\section{INTRODUCTION}

A holistic view of the problem of modeling the development of technological integration.

Technological integration is a phenomenon that can transform the external and internal relationships of business entities that are integrated into each other, or closely interact for the period of performing certain tasks. First of all, this concerns the development of technologies focused on process innovations, including the production of high-tech products of deep processing, as well as technologies for managing industrial complexes. The ultimate goal of these changes is to generate added value along the production chain, as well as to digitalize the economy. The study of issues and prospects for the development of technological integration is due to the global challenges of the economic crisis, the sharp deterioration of How to cite: Miller, A., Miller, M. (2020). Models of Technological Integration Development. In Proceedings of the 25th International Scientific Conference Strategic Management and Decision Support Systems in Strategic Management. https://doi.org/10.46541/978-86-7233-386-2_8 
the environmental situation on a global scale, as well as restrictions and barriers to the free circulation of innovative ideas and developments.

Technological integration contributes to the development of intelligent production technologies based on a system of interconnected and complementary production complexes. In contrast to the existing concepts of managing organizations that operate in the face of external challenges, the development of technology is based on organizational and process modeling, which offers a clear set of tools for simplifying and reducing the timing of the transition to the level of high technological redistribution based on the state of the resource base, using existing and new economic ties inside and outside of industrial complexes. Digital information processing technologies focused on modeling complex technological processes are of particular importance in the development of technological integration.

\section{METHODOLOGY}

\subsection{Structural and functional approach}

As a methodological framework there was applied structural-functional approach, which is based on the methods of analysis and synthesis in the study of the technology integration development in integrity, unity and relationship of its constituent parts; economic-statistical methods (grouping, typing, plotting time series, determination of ratings, etc.) to analyze and compile statistical information, identify trends and characteristics of scientific and technological development of industrial enterprises. The implementation of the approach is facilitated by the use of a computational and analytical method for modeling the development of technological integration of economic entities; for visualizing the obtained results there was used a graphical method.

The essence of the structural and functional approach is that technological integration is considered as a dynamic process of transforming the flows of production resources in the form of new technologies at the enterprise level, as well as on a global scale by using the reserves of internal and external development (Miller \& Davidenko, 2019). In the definition there can be seen a connection with the theory of structural functionalism, especially if the socio-economic system is interpreted in the light of stable complexes, rules and norms (Vanderstraeten, 2019). But there is a distinctive feature when determining the object and subject of technological integration, the system of economic relations for regulating the flow of production resources in the form of applied technologies is taken as a basis, since it will be subject to the greatest transformation in case of detection of problem areas in the organization of production.

The key place among the elements of the structural and functional approach is occupied by tools that allow formalizing the procedure for evaluating the effectiveness of the development of technological integration in a set of measures agreed on terms, resources and performers. The toolkit allows to:

- reveal the causal mechanisms of commercialization of ideas and profit (the direct Causal Mechanisms of Profit, "DCMP"), focused on innovation, technological change and meeting the need for fixed assets (Kim \& Lee, 2018),

- determine the key forms of interaction between structures for the purpose of forming economic, technological and social thinking within a single ecosystem (Audretsch \& Link, 2018),

- implement innovations based on internal and external knowledge flows. State programs for subsidizing research and scientific and technological developments on the basis of mandatory involvement of universities in the implementation of innovative projects (Guerrero, Urbano \& Herrera, 2019; Colombelli, \& Quatraro, 2019),

- develop agglomeration economy through geographical concentration of innovations and growth of regional innovation capacity ("RIC"), expressed by the average number of patents, innovations and small innovative firms (Hamidi, Zandiatashbar \& Bonakdar, 2019),

- accelerate the process of adaptation to the heterogeneity of integration participants while expanding the areas of global cooperation in the field of technological innovations in order to maximize the impact of external innovations (Huang, Chen, Ye \& Wang, 2019).

At its core, basing technological integration on a structural and functional approach contributes to the integration of production, technological, and financial and economic content into a single data set. According to domestic and foreign experts, the transition to the level of intelligent industrial production is determined by the readiness of enterprises to implement interactive programs of innovative projects on joint production sites by forming a common bank of breakthrough technologies, after which the management system of integrated economic complexes will be able to move to a new level of production organization that meets the requirements of high returns on all types of invested capital.

\section{RESULTS OF RESEARCH}

\subsection{Organizational model for the technology integration development}

The research of the processes of selecting models for the development of technological integration in the industrial sector of the economy has shown that today there are two approaches that are most important and play a key role in the development of technological integration: organizational and process modeling. 
Organizational modeling should be considered as the process of creating analogs to real objects or processes, which allows isolating the key properties and essential characteristics that correspond to the simulated objects (Visnjic, Ringov \& Arts 2019). This does not take into account minor properties and characteristics. Among the tools that make it possible to create organizational modeling, we should highlight the formalization, which is used, on the one hand, to organize knowledge about the object, and on the other - as a way to provide information.

The formalization of the organizational model for the development of technological integration is reflected in the following documents: standards, statutes, regulations, methods, instructions, rules, etc. The main purpose of these documents is to establish a procedure for distributing functions, responsibilities and rights among participants in technological integration (Pfohl, Yahsi \& Kurnaz, 2017) The effectiveness of formalization of the organizational model is achieved, on the one hand, due to the action of objective laws that form specific conditions for the implementation of technological integration, on the other hand, due to the consistency of documents of different levels of action, their common perception and application. Implementation of the organizational model of technological integration is possible in the form of graphs and diagrams.

In organizational models of technological integration there can be distinguished two types, which are divided according to the signs of their formation. The first type allows revealing the characteristic features of the relations of the original and the reflection of its properties, as well as the principles of the model functioning. The second type reveals the reasons for changing the properties and relationships of the generated model, and its relationship with the properties and relationships of the original. The first type allows us to distinguish logical (symbolic, figurative and figurative-sign); semantic and material (geometric functional, functional-geometric) models. The second type of organizational models of technological integration includes mathematical, conditional, and analog models.

This division of organizational models of the technological integration development into types allows us to reflect their key characteristics. Considering the model of technological integration development as a model of a complex system, it should be emphasized that it reveals all the features of a complex type and can contain a variety of representations.

The development process of technology integration may involve the use of models that reflect the functions of technological integration; resources to fully implement the functions; the processes to meet the objectives of technological integration; the composition and structure of participants in technology integration, providing structural interrelation of all elements of the relationship; the variety of financial, material, informational and other flows characteristic of full the functioning of technological integration (Park, Choi \& Hong, 2015).

Thus, the organizational model of technological integration development is a complex characteristic that allows revealing graphically or descriptively the elements of technological integration, as well as reflecting the completeness of their relationship. The main task of the organizational model of technological integration development is to simplify the system representation of existing or projected technological integration on the basis of analogies. The organizational model of technological integration development should be considered as a tool for purposeful research of technological integration, which will allow anticipating all possible variants of technological integration changes using changes in the initial assumptions. The organizational model is actually a means of simplifying the consideration of technological integration, since it allows studying it in relation to the essential characteristics of technological integration, leveling the actions of non- essential changes.

The formed organizational model of technological integration development reflects the characteristic features of its system-forming elements. Formation of the organizational model, as well as its design is carried out based on the strategic plan of the business entity. At the same time, the structural elements of a business entity significantly affect their strategy, since it determines the ability to respond quickly to the action of environmental factors. The organizational model of technological integration development should not be considered as a static model, since it changes in the course of the business entity's activity. It is impossible to maintain the static organizational model in relation to the conditions of dynamic development of the external environment (Boschma \& Fornahl, 2011).

In the process of forming an organizational model for the development of technological integration, a special place is taken by taking into account the interests of all its participants, since it is necessary to ensure the priority position of the initiator of its creation, based on the fact that it bears both investment and financial risks. It is also necessary to take into account possible differences in the legal status of each participant of technological integration, as well as their right to independence as an economic entity.

The formation of an organizational model for the development of technological integration is carried out in strict accordance with the organizational and strategic lines, taking into account the existing experience of participants, as well as technological, information and other achievements in the rapidly changing conditions and environmental factors.

The organizational model of technological integration development can be disclosed in the form of system modules that are interconnected (figure 1).

Considering each of the modules, it is necessary to select the "resources" module, which shows the sources of formation of all types of production resources, the total volume, the procedural order of their receipt, the direction of use in the main activity of the business entity.

The "structure" module shows the order of interaction of all elements of technological integration. This module includes the technological structure, financial and organizational structure. At the same time, the process of their formation is directly connected to the processes related to ensuring the development of technological integration, which is reflected in the "processes" module. The formation of an organizational model for the development of technological integration should begin with identifying the main products of the business entity, revealing the processes of its production, leveling the "secondary" processes and developing the existing ones. 


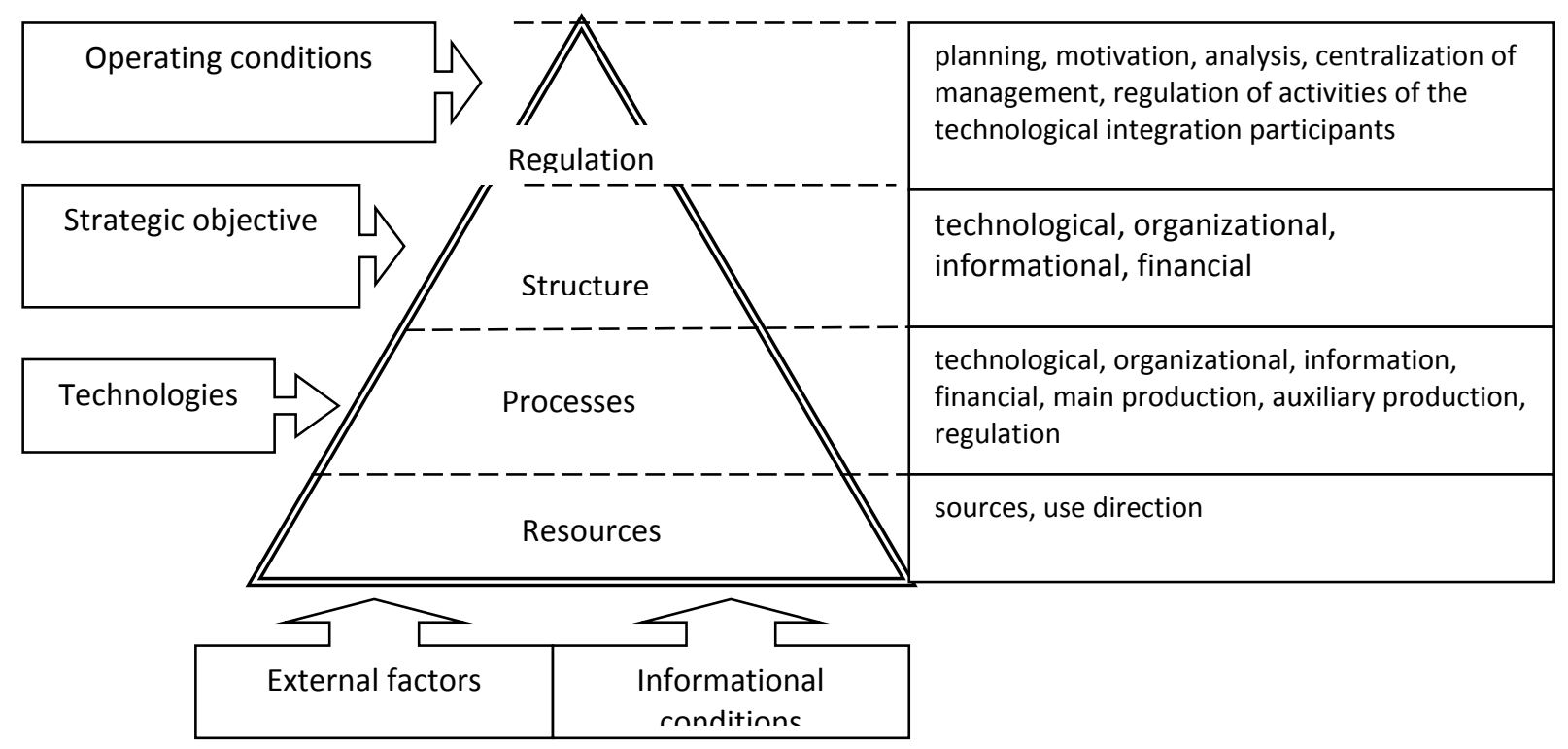

Figure 1: Organizational model of the technological integration development Source: Author's research

To provide the "regulation" module for technological integration, it is necessary to take into account such processes as planning, motivation, analysis; centralization of management and regulation of the activities of participants in the development of technological integration.

The development of technological integration takes place with the active participation and influence of factors, both within the business entity and outside it. Thus, dynamic, structural and static aspects of the development of technological integration are updated. In parallel, the functioning of the business entity is being streamlined, which is based on regulatory processes, compliance with business conditions and life cycle parameters (Proskuryakova, Meissner $\& \underline{\text { Rudnik}}$, 2017).

For the purpose of forming an organizational model for the technological integration development, a specialized modeling tool plays a significant role. The main advantages of the instrumental approach to organizational modeling of technological integration are: the presence of a standardized approach and improving the quality of design; the creation of a single integrated documented system; the ability to reuse the generated models; the ability to test the simulated processes; availability of stable feedback from all participants of technological integration; cultivation of generally accepted terminology. The problem stage of determining the generally accepted approach in relation to organizational models is the achievement of a given level of standardization. However, the formalization of modeling methods is a good basis for standardization. This is largely facilitated by the use of an instrumental approach in organizational modeling.

Of course, modeling is possible without the use of a tool approach, but it is in many ways that makes this process easier. The use of the tool approach is achieved through diagrams, graphical symbols, and links that are set in advance and thus ensure compliance with the unified methodology of model design. Consequently, the processes of creating their own standards are updated, allowing the selection of methods and tools for target use in modeling technological integration. A reserve in organizational modeling is an information-oriented mechanism for regulating technological integration based on modern information technologies based on the availability of information systems (Oughton, Frias, Dohler, Whalley et al., 2018). This, to a large extent, leads to the full functioning of technological integration, to the positive dynamics of the vector of adaptability, as well as to increased competitiveness.

With the development of organizational modeling, the process of modernization and improvement of its tools takes place. As a result, there are built organizational models, both for the initial process of technological integration and for those that are being reorganized in the process of development. It should be emphasized that each business entity should correspond to the organizational model for the development of technological integration. Detailed elements of technological integration contribute to the successful functioning, improvement and development of all participants of the business entity as a system. The key point is the formation of an adequate organizational model that meets the requirements of the information system. Meeting the requirements of the information system contributes to making operational decisions aimed at improving communication and integration of participants in technological integration, and maintaining a full cycle of regulation of the main and auxiliary production processes of the business entity.

Thus, the presence of an organizational model for the technological integration development contributes to the formation of a system of interrelated components. In order to achieve the effectiveness of regulation of this complex system of 
relations, the use of a process approach based on the separation of business processes of technological integration and their regulation is updated.

\subsection{Process model of technological integration development}

Economic entities have a complex structure, defined by a wide range of their main activities, the presence of diverse participants, the presence of structured elements of technological integration, which are influenced by the entire range of environmental factors. The data show the difficulties of applying the process approach, both to the regulation of relations between participants in the development of technological integration, and management processes aimed at the main activity. The formation of a process model for the development of technological integration should strictly follow the conceptual framework of the strategy for the development of technological integration, implement preventive measures to neutralize the negative effects of environmental factors, and adhere to the format of existing organizational structures (Druzhinin \& Dong, 2018). The process model of technological integration development reflects the entire set of tools for their regulation: planning, analysis, control, organization of the main cycle of production activities , management technology, business process maps, list of regulations, procedures execution regulations, list of indicators, evaluation lists for participants of technological integration, motivation regulations, document flow diagram, operational reporting forms. The process model for the development of technological integration is the basis for the formation of a long-term process regulation, as approved procedures for the implementation of the process. It should be correctly assessed that the quality of the final product is formed by the quality of the organization and execution of the business process. At the same time, the process should be considered as a stable, purposeful set of interrelated types of main production activities, which, in turn, involves a certain technology for converting incoming initial production resources and outgoing finished products that are in demand by consumers. The presence of a regulated and formalized procedure makes it possible to regulate demand, strictly measuring the vector direction of the specified business process. Time costs are minimized by optimizing the internal structure of the business process (Kovacs, 2018).

The process model of technological integration development can be represented, on the one hand, as a set of independent business processes of their participants, on the other hand - as separate business processes (figure 2).

\section{Real opportunities of The effect of environmental technological integration factors}

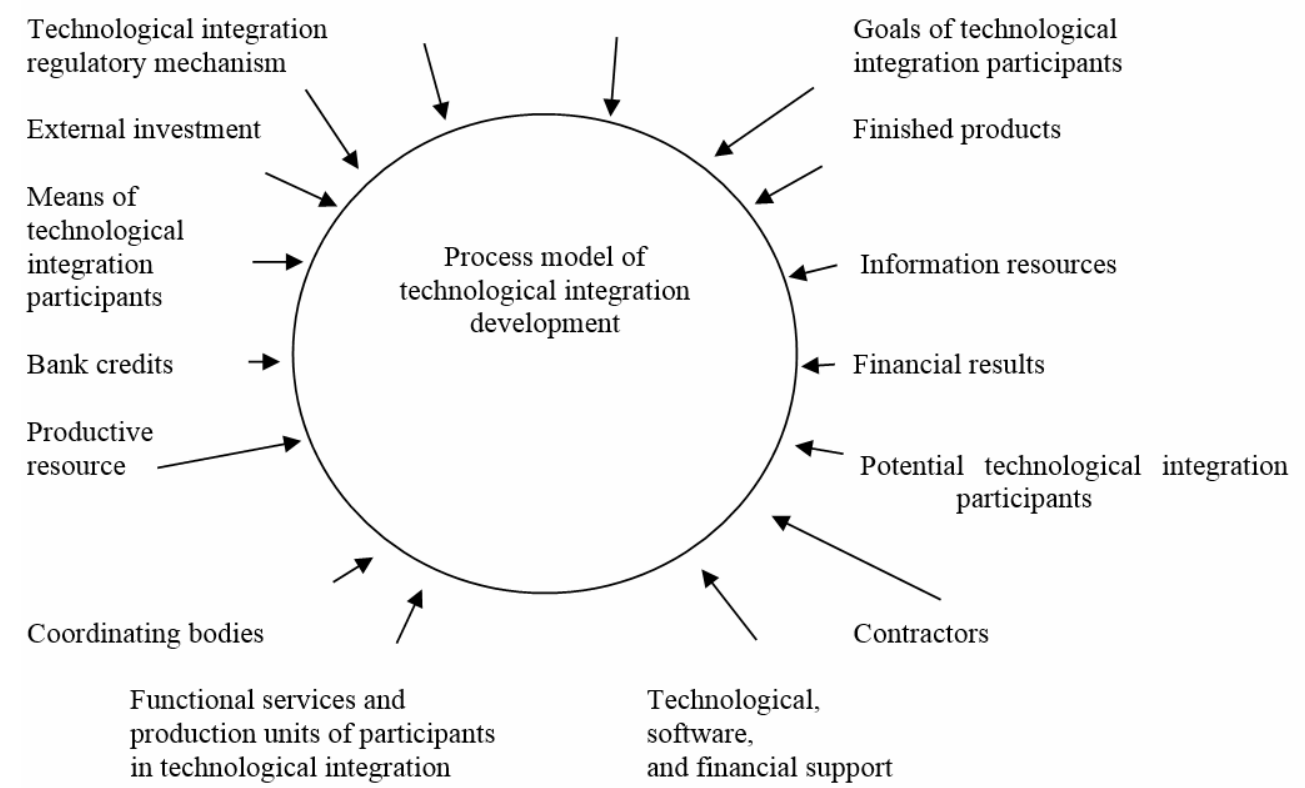

Figure 2: Process model of technological integration development Source: Author's research

Decomposition of the process model of technological integration development in the form of a conditional method makes it possible to see the entire set of technological integration convenient for real understanding. This makes it possible to clearly define the structural elements of technological integration and reveal the main relationships between them. The degree of decomposition depth is determined by the goals of process modeling.

The process model of technological integration development includes the following information items:

- nomenclature list of sequential functions, procedures, and operations required to perform in order to achieve the effectiveness of technological integration development,

- a minimum list of entities in the form of specific individuals, services, and divisions as the main performers of business process functions, 
- defining the procedure for relationships and interactions between participants in the development of technological integration when performing the full functions of business processes,

- development of accounting, control and regulation mechanisms in relation to implemented business processes,

- selection of parameters that reflect the degree of completeness of the execution of each of the functions separately, and processes as a whole,

- creating a list of outgoing and incoming information, formalized in the form of a specific document, which is performed during the implementation of each process,

- defining all types of resources necessary for the full implementation of each of the process functions,

- availability of documentation regulating the execution of each individual business process.

As a rule, the process of technological integration development depends on the nature of production activities, as well as on the nature of the final product. They can be divided into three groups: main processes, supporting processes, and regulatory processes (Wu, Harrigan, Ang et al, 2019). The main business processes are aimed at creating added value, generating profits, and producing final products that are in demand by potential consumers.

Supporting processes are focused on building the infrastructure of technological integration and providing the necessary resources to the main business processes. With the help of regulatory processes, the actions of participants in technological integration are coordinated, as well as the functions of planning, analysis, control, and motivation are performed.

At the same time, a number of authors (Harrigan, Di Guardo \& Cowgill, 2017) identify the fourth group of processes for the development of technological integration - business processes of development aimed at achieving profit in the forecast period and ensuring the progressive development of technological integration. It should be emphasized that the processes of technological integration development can be classified as regulatory processes, since a number of their main characteristics are very similar, what makes it possible to integrate them into the algorithm of the corresponding processes. However, for the purpose of objective justification of the process model for the development of technological integration, it is still necessary to emphasize that the existing traditional typologies of business processes do not fully reflect the characteristics inherent in the development processes. Groups of processes that are typical for the development of technological integration are presented in table 1.

\subsection{Decomposition of the process model of technological integration development}

The decomposition of the process model for the development of technological integration is primarily related to the need to identify the main and supporting processes, the subjects of which, as a rule, are the participants of technological integration. (figure 3). The regulatory processes are managed by managers of business entities (Meissner \& Carayannis, 2017). Participants in technological integration are also subjects of development processes, which allow them to coordinate their interests and strategic goals. The need to identify business processes in order to form specific process models for the development of technological integration should be carried out with certain principles in mind:

Table 1. Classification characteristics of the technological integration development processes

\begin{tabular}{|l|l|l|l|}
\hline Process groups & Process subjects & Characteristics & Goal \\
\hline Main processes & $\begin{array}{l}\text { Participants in } \\
\text { technological } \\
\text { integration }\end{array}$ & $\begin{array}{l}\text { Aimed at the production of main } \\
\text { products. Generate profit. } \\
\text { Responsible for the development } \\
\text { strategy }\end{array}$ & Meeting the needs of consumers \\
\hline Supporting processes & $\begin{array}{l}\text { Participants in } \\
\text { technological } \\
\text { integration }\end{array}$ & $\begin{array}{l}\text { Are aimed at ensuring the main } \\
\text { processes. There is no direct link to } \\
\text { the final product. Generate costs. }\end{array}$ & $\begin{array}{l}\text { Providing resources for the main } \\
\text { processes }\end{array}$ \\
\hline Regulatory processes & $\begin{array}{l}\text { Managers of a } \\
\text { business entity }\end{array}$ & $\begin{array}{l}\text { Regulatory processes are directly } \\
\text { related to the core business }\end{array}$ & $\begin{array}{l}\text { Regulation of the activities of } \\
\text { participants in technological } \\
\text { integration }\end{array}$ \\
\hline Development process & $\begin{array}{l}\text { Participants in } \\
\text { technological } \\
\text { integration }\end{array}$ & $\begin{array}{l}\text { Coordinates interests and strategies } \\
\text { of technology integration participants }\end{array}$ & $\begin{array}{l}\text { Coordination of investment and } \\
\text { financial direction of development }\end{array}$ \\
\hline
\end{tabular}

Source: Author's research

- all processes must have clearly defined contours,

- every process must have input, output, and subjects of technological integration,

- a process must have process subjects, criteria and parameters, resource support, methods and methods for converting input and output, and regulatory techniques,

- every process must contain factors that are focused on a specific economic result,

- $\quad$ there should be a possibility to exclude non-resulting processes.

In the figure 4 there is presented decomposition of the supporting and regulatory processes of technological integration in the form of a business process system. 
The effectiveness of the process model of technological integration development is determined not only by optimizing the existing business processes of the participants of technological integration, but also by identifying business processes aimed at performing functions, operations and procedures (Zambelli, Fredholm \& Venkatachalam, 2017). The allocation of support and regulatory processes greatly facilitates the use of the results achieved at the output of these groups, since they actually serve as combined resources for the main processes and processes of technological integration development.

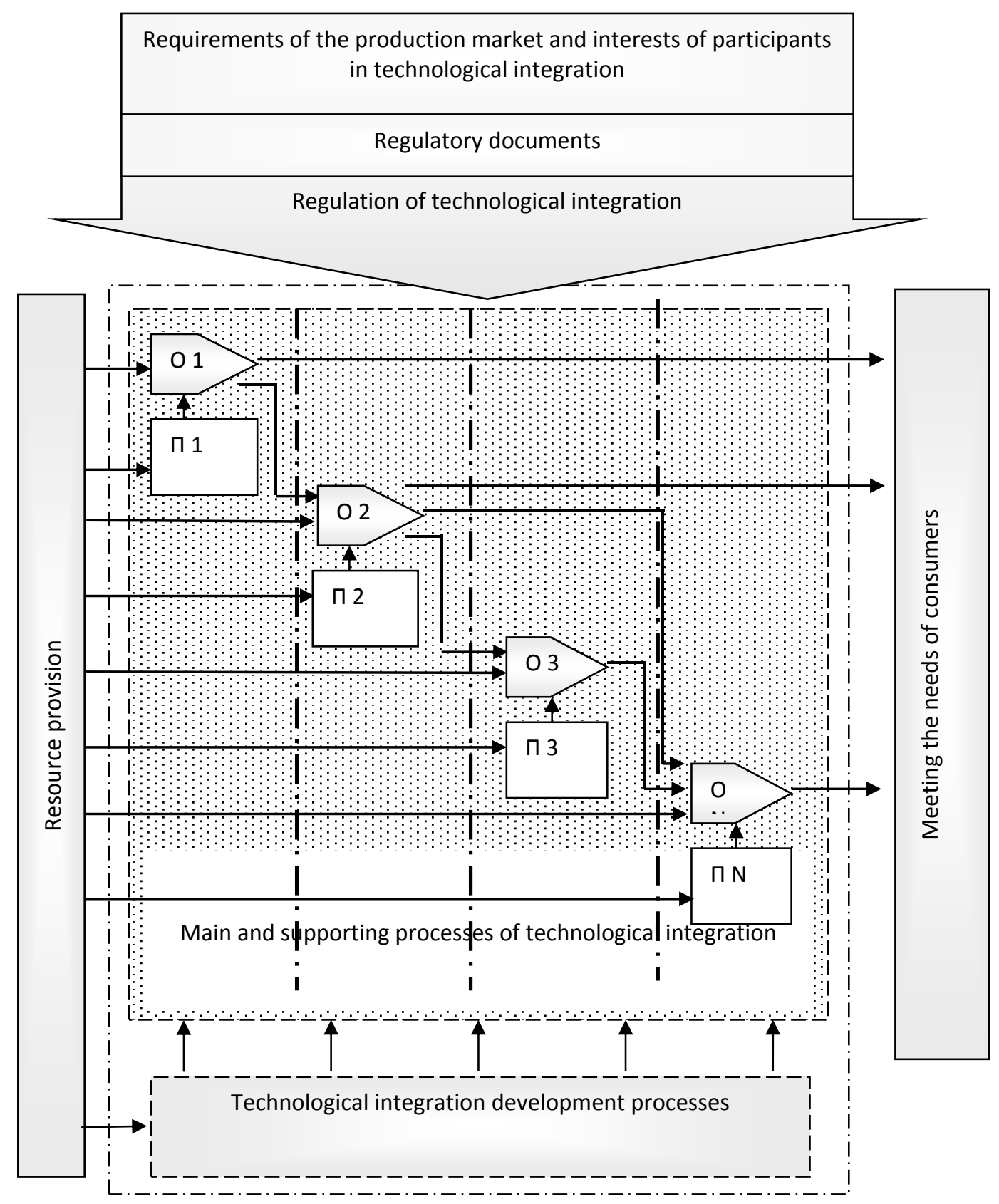

Figure 3: Decomposition of the process model of technological integration development Source: Author's research

In these groups, by prior agreement with the subjects of the main processes and processes of development (O), it is possible to include those supporting and regulatory processes $(\mathrm{P})$ that allow providing of specific internal results aimed at the action of the entire set of main processes and processes of development. As a basic solution, information support (software products), compliance with environmental safety, innovative processes, financial and legal support processes, and regulation of relations with contractors can be attributed to these groups. 


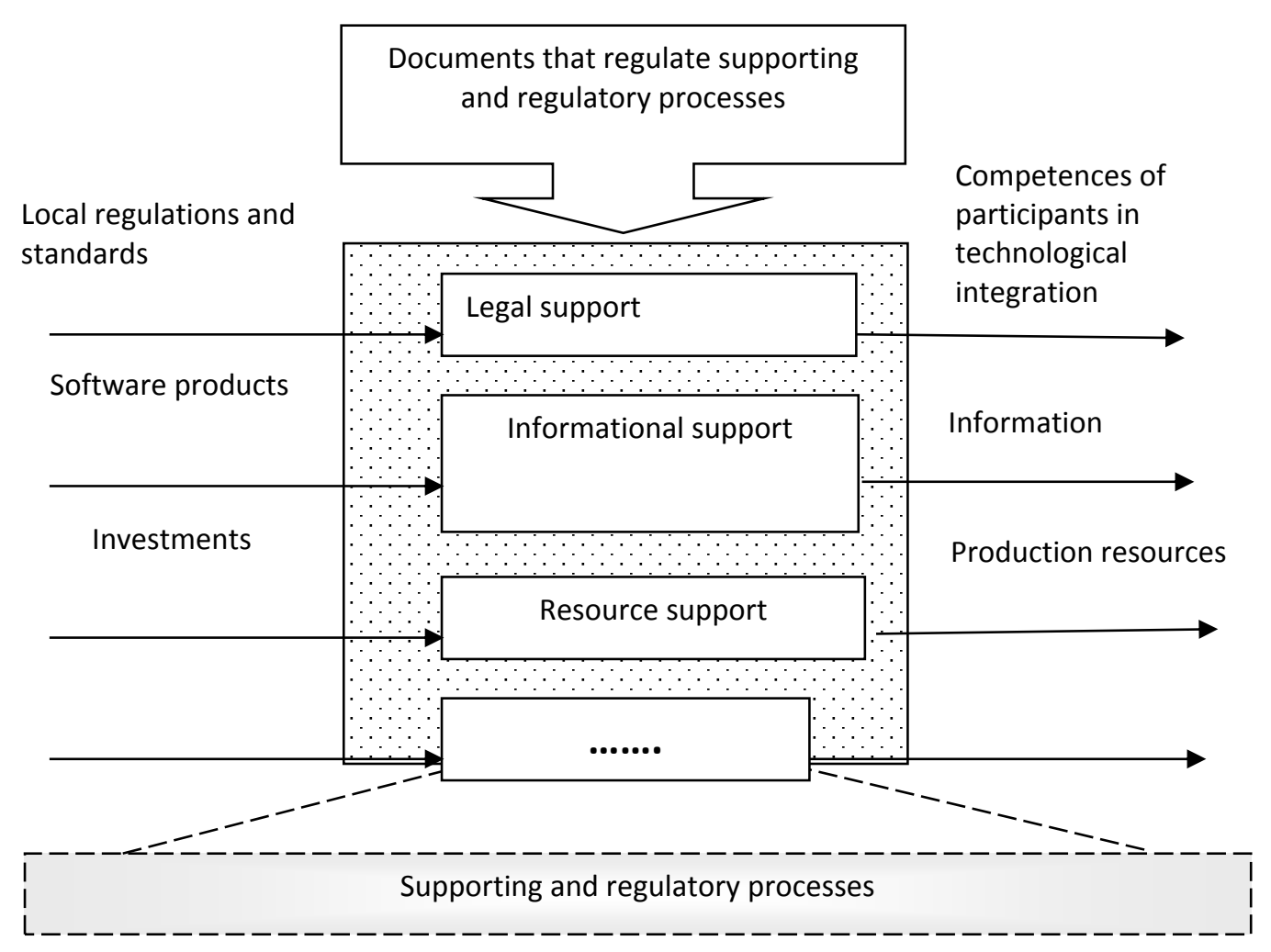

Figure 4: Decomposition of supporting and regulatory processes of technological integration Source: Author's research

The set of regulatory methods is formed in close connection with the key functions and specifics of the organizational structure. The formed set of regulatory methods usually changes in the course of the main activity of the business entity.

1. Making selection of the tools there must be considered the following aspects (Richter, Kraus, Brem, Durst \& Giselbrecht, 2017):

2. 1) the purpose of the project;

3. requirements for information support that reflects the content of the business process and is necessary for analysis and decision -making;

4. features of the algorithm and certain software products used in business process modeling;

5. capabilities of software products required for documenting processes.

The tools needed to create a process for regulating technological integration can be divided into manual tools (MS Office, MS Visio), as well as automated tools (application software systems - IDEF, ARIS, AllFusion). Manual tools are used to detail the process of regulating technological integration, usually in the text version. This is due to the convenience of reading and understanding all the ongoing processes by participants of technological integration who do not have special training. Automated software tools are more focused on both visual and text design. These tools are more time-consuming to set up, are expensive, but are more adapted for the purposes of current and subsequent evaluation and optimization.

1. The process model of technological integration is aimed at achieving the following goals;

2. Standardization of business processes of technological integration and their regulation, which allows ensuring the stability of their passage and reducing to a minimum the cost of their implementation. When expanding production activities, the involvement of new participants in technological integration significantly speeds up the procedure for applying regulatory processes, as well as modern technologies implemented in the course of technological integration development;

3. Building a system of criteria and indicators for the development of technological integration in relation to the regulation of the entire set of business processes;

4. Preservation of the experience of joint activities by participants of technological integration and involvement of new subjects of relations in this process;

5. Evaluating the prospects for technological integration, improving the quality of existing business processes, and increasing the level of customer satisfaction; 
6. Involving the subjects of technological integration in the process of their formation and development, as well as leveling inter-organizational and inter-functional contradictions by involving the participants of technological integration in the creation of system regulations that provide for their powers and main functions;

7. Increasing the flexibility of technological integration to respond to changes in the production market;

8. Availability of the ability to certify the processes of technological integration development in accordance with current standards;

9. Optimization of the document flow procedure that regulates the processes of technological integration development;

10. "Transparency" of technological integration development for all their participants, as well as investment processes.

\section{CONCLUSION}

Thus, the organizational model of technological integration development as a form of its complex characteristic can usually be represented in the relationship of four interrelated modules: regulation, structure, processes, and resources. The formation of the organizational model is due to the tools of organizational design, focused on the organization and functioning of technological integration, their organizational and strategic orientation, the use of modern technologies, existing experience, information, taking into account the leveling of the action of environmental factors.

An important role in organizational modeling is played by business process modeling aimed at ensuring the regulation of technological integration, evaluation, coordination and regulation of their development processes. The process model of technological integration development is designed to determine the vector direction of coordination of actions of all participants of technological integration to achieve goals. Process modeling is based on the principle of processes "nesting", which allows for the decomposition of process models for the development of technological integration, providing a consistent movement from the general to the particular.

\section{ACKNOWLEDGMENTS}

The reported study was funded by RFBR according to the research project № 19-010-00081.

\section{REFERENCES}

Audretsch, D.B. \& Link, A.N. (2018) Innovation capital //J Technol Transf ,43, 1760-1767. https://doi.org/10.1007/s10961-018-9700-6

Boschma, R. \& Fornahl, D. (2011) Cluster Evolution and a Roadmap for Future Research // Regional Studies, 45 (10), 1295-1298. https://doi.org/10.1080/00343404.2011.633253

Colombelli, A. \& Quatraro, F. (2019) Green start-ups and spillovers from clean and dirty technologies // Small

Business Economics, 52 (4), 773-792. https://doi.org/10.1007/s11187-017-9934-y

Druzhinin, A. G. \& Dong, Y. (2018) One Belt - One Road Initiative: A Window of Opportunity for Russia's

Western Border Regions // Baltic Region, 10 (2), 39 - 55. https://doi.org/10.5922/2079-8555-2018-2-3

Guerrero, M., Urbano, D. \& Herrera, F. (2019) Innovation practices in Emerging Economies: Do University partnerships matter? // Journal of Technology Transfer, 44 (2), 615-646. https://doi.org/10.1007/s10961-017-9578-8 Hamidi, S., Zandiatashbar, A. \& Bonakdar, A. (2019) The relationship between regional compactness and regional innovation capacity (RIC): Empirical evidence from a national study // Technological Forecasting and Social Change, 142, 394-402. https://doi.org/10.1016/j.techfore.2018.07.026

Harrigan, K.R., Di Guardo, M.C. \& Cowgill, B. (2017) Multiplicative-innovation synergies: tests in technological acquisitions // The Journal of Techology Transfer, 42 (5), 1212 - 1233.

https://doi.org/10.1007/s10961-016-9514-3

Huang, Sh. F., Chen, J., Ye, W. W. \& Wang K. (2019) The effect of external partner heterogeneity on open innovation: the moderating role of the technological regime // Technology Analysis \& Strategic Management, 31 (5), 593-605. https://doi.org/10.1080/09537325.2018.1529301

Kim, IH. S. \& Lee, BY. M. (2018) Direct causal mechanisms of profit: dominant paradigm of profit seeking // Technology Analysis \& Strategic Management, 31 (4), 371-387. https://doi.org/10.1080/09537325.2018.1516863 Kovacs, O. (2018) The dark Corners of Industry 4.0 - Grounding Economic Governance 2.0 // Technology in 
Society, 55, 140-145. https://doi.org/10.1016/j.techsoc.2018.07.009

Meissner, D. \& Carayannis, E.G. (2017) Value generation from Industry-science Linkages in light of Targeted open Innovation // Journal of Knowledge Management, 21 (2), 295-307.

https://doi.org/10.1108/JKM-11-2016-0510

Miller, A.E. \& Davidenko, L.M. (2019) Structural-functional approach to the research of technological integration // Herald of Omsk University. Series "Economics", 17 (3), 59-69.

https://doi.org/10.25513/1812-3988.2019.17(3).59-69

Oughton, E.J., Frias, Z., Dohler, M., Whalley, J. et al. (2018) The strategic national infrastructure assessment of digital communications // Digital Policy Regulation and Governance, 20 (3), 197-210.

https://doi.org/10.1108/DPRG-02-2018-0004

Park, S. R., Choi, D. Y. \& Hong, P. (2015) Club convergence and factors of digital divide across countries

//Technological Forecasting and Social Change, 96, 92-100. https://doi.org/10.1016/j.techfore.2015.02.011

Pfohl, H. C., Yahsi, B. \& Kurnaz, T. (2017) Concept and diffusion-factors of industry 4.0 in the supply chain //

Dynamics in Logistics, Springer, Cham, 381-390. https://doi.org/10.1007/978-3-319-45117-6_33

Proskuryakova, L. N., Meissner, D. \& Rudnik, P. B. (2017) The use of technology platforms as a policy tool to address research challenges and technology transfer // The Journal of Technology Transfer, 42 (1), 206-227. http://doi.org/10.1007/s10961-015-9421-z

Richter, C., Kraus, S., Brem, A., Durst, S. \& Giselbrecht, C. (2017) Digital entrepreneurship: Innovative business models for the sharing economy // Creativity and Innovation Management, 26 (3), 300-310.

https://doi.org/10.1111/caim.12227

Vanderstraeten, R. (2019) Systems everywhere? // Systems Research and behavioral Science, 36 (3) 255-262. https://doi.org/10.1002/sres.2596

Visnjic, I., Ringov, D.\& Arts S. (2019) Which Service? How Industry Conditions Shape Firms' Service-Type Choices // Journal of Product Innovation Management, 36 (3). 381-407. https://doi.org/10.1111/jpim.12483

Wu, J., Harrigan, K.R., Ang, S.H. et al. (2019) The impact of imitation strategy and R\&D resources on incremental and radical innovation: evidence from Chinese manufacturing firms // The Journal of Techology Transfer, 44 (1), 210 230. https://doi.org/10.1007/s10961-017-9621-9

Zambelli, S., Fredholm, T. \& Venkatachalam, R. (2017) Robust Measurement of National Technological Progress // Structural Change and Economic Dynamics, 42, 38-55. https://doi.org/10.1016/j.strueco.2017.05.001 